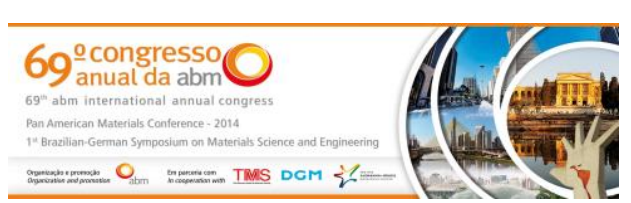

Tema: Estampagem

\title{
ESTUDO DO RETORNO ELÁSTICO PARA O AÇO DUAL PHASE COM USO DA TÉCNICA DE CISALHAMENTO PLANAR $^{\star}$
}

\section{Resumo}

\author{
Douglas Ferreira Senra ${ }^{1}$ \\ Elaine Carballo Siqueira Corrêa \\ Maria Teresa Paulino Aguilar ${ }^{3}$ \\ Wellington Lopes ${ }^{4}$
}

O estudo do retorno elástico dos materiais metálicos constitui alvo de pesquisa há muitos anos, abordando diversos parâmetros relacionados à ocorrência desse problema comum em operações de estampagem de chapas como a quantidade de deformação prévia, o tipo de material e o estado inicial do mesmo em termos estruturais. No entanto, apesar de serem adotados diversos métodos experimentais para exibir a quantidade de deformação que o material exibe de modo indesejado percebe-se a dificuldade de a mesma ser identificada corretamente como, por exemplo, ensaios de dobramento. Diante do exposto, este trabalho apresenta o estudo do retorno elástico exibido pelo aço Dual Phase após ciclos de deformação plástica em cisalhamento cíclico (cisalhamento direto e reverso) em função da quantidade de pré-deformação em cisalhamento direto e da taxa de deformação adotada nos ensaios. Os resultados indicaram o sucesso do uso da técnica de cisalhamento para o estudo do retorno elástico do aço Dual Phase e a influência da quantidade de deformação cíclica e da taxa de deformação no retorno elástico apresentado por esse aço, sendo maior o efeito exibido por esta última variável.

Palavras-chave: Aço Dual Phase; Cisalhamento planar; Retorno elástico.

\section{STUDY OF SPRINGBACK FOR THE DUAL PHASE STEEL WITH THE PLANAR SHEARING TEST}

\section{Abstract}

The study of the springback of metallic materials has been made for many years, describing different aspects related to the occurrence of this problem commonly observed in processes of sheet forming such as the amount of previous strain, the type, the initial state and the microstructure of materials. However, although have been used diverse experimental methods to study the springback, that is, the amount of strain that the material exhibits when the mechanical effort is removed during a operation of metal forming, this phenomenon not is completely understood with the traditional techniques such as the bending tests. This manner, this work presents the study of the springback exhibited by the Dual Phase steel after cycles of plastic deformation composed by cyclic shearing tests (direct and reverse) for different values of amplitude of cyclic strain and the strain rate. The results indicated the success of the planar shearing test for the study of the springback of Dual Phase steel sheets and the influence of the amount of the cyclic strain and the rate strain on the springback value presented by this steel, being higher the effect exhibited by this last one variable.

Keywords: Dual Phase steel; shearing test and Springback.

1 Graduando em Engenharia de Materiais, Centro Federal de Educação Tecnológica de Minas Gerais, CEFET-MG, Belo Horizonte, MG, Brasil.

2 Engenheira Mecânica, Doutora, Professora, Departamento de Engenharia de Materiais, Centro Federal de Educação Tecnológica de Minas Gerais, CEFET-MG, Belo Horizonte, MG, Brasil.

3 Engenheira Mecânica, Doutora, Professora, Departamento de Engenharia de Materiais e Construção, Universidade Federal de Minas Gerais, UFMG, Belo Horizonte, MG, Brasil.

4 Engenheiro Mecânico, Doutor, Professor, Departamento de Engenharia de Materiais, Centro Federal de Educação Tecnológica de Minas Gerais, CEFET-MG, Belo Horizonte, MG, Brasil.

\footnotetext{
* Contribuição técnica ao 69 Congresso Anual da ABM - Internacional e ao 14ํㅡㄹ ENEMET - Encontro Nacional de Estudantes de Engenharia Metalúrgica, de Materiais e de Minas, 21 a 25 de julho de 2014, São Paulo, SP, Brasil.
} 


\section{INTRODUÇÃO}

A obtenção de produtos com propriedades adequadas ao uso requer, dentre outros aspectos, o conhecimento das diferentes condições de processamento aplicadas aos diversos tipos de materiais, assim como às características intrínsecas de cada material que estiver sendo utilizado. Essas informações são constantemente utilizadas por meio de simulação numérica que utilizam modelos variados com o objetivo de melhorar sistematicamente essas operações. Contudo, é de extrema importância para esses estudos que os pesquisadores saibam identificar as relações existentes entre as mudanças das condições de solicitação termomecânica aplicadas aos materiais e as respectivas respostas macroscópicas apresentadas pelos mesmos.

Neste aspecto, cita-se como exemplo, a necessidade do conhecimento do retorno elastoplástico nas operações de estampagem de chapas, fenômeno este que ocorre após a retirada do esforço mecânico responsável pela mudança de forma do material. Este efeito caracteriza-se por uma distorção elástica, sendo mais expressivo em chapas com dureza maior e espessura menor. Alguns autores destacam ainda a associação do retorno elastoplástico com o efeito Bauschinger, fenômeno este caracterizado pela queda da tensão de fluxo no início do recarregamento decorrente da mudança do sentido de aplicação do primeiro esforço mecânico, como exemplo, tração acompanhada por compressão como resultado da reorganização das subestruturas de discordâncias [1].

O efeito Bauschinger serve como indicador da ocorrência do retorno elástico, além de influenciar na sua amplitude [2-4].

Várias técnicas têm sido usadas para avaliar o retorno elástico de diferentes tipos de materiais submetidos a diversos processos de conformação mecânica, em destaque, a operação de estampagem por dobramento. Neste caso, faz-se uso, por exemplo, da medição do ângulo final e compara-se esse valor com o ângulo obtido ao término do dobramento [5], dos métodos de simulação numérica com uso de elementos finitos [6], e mais recentemente, da técnica de cisalhamento planar [7].

Considerando o exposto acima, este trabalho pretende demonstrar o uso da técnica de cisalhamento planar para permitir o estudo do retorno elástico do aço Dual Phase mediante a combinação de esforços de cisalhamento direto e reverso, ou seja, uma condição capaz de criar o carregamento do tipo cíclico, observando assim, o retorno elástico apresentado pelo aço Dual Phase após a inversão do sentido de deformação plástica (mudança do cisalhamento direto para o cisalhamento reverso). Neste caso, duas variáveis foram escolhidas para estudar a evolução do retorno elástico do aço Dual Phase: a amplitude de deformação cíclica e a taxa de deformação, parâmetros estes que determinam, por exemplo, os limites de deformação de objetos submetidos às operações de conformação mecânica.

\section{MATERIAIS E MÉTODOS}

\subsection{Material}

Neste trabalho foram utilizadas chapas de aço Dual Phase com a seguinte composição química: $0,154 \% \mathrm{C}, 1,5 \% \mathrm{Mn}, 0,042 \% \mathrm{Al}, 0,016 \% \mathrm{Nb}, 0,52 \% \mathrm{Si}, 0,04 \% \mathrm{Ni}$, $0,03 \% \mathrm{Cr}, 0,01 \% \mathrm{Mo}, 0,01 \% \mathrm{~V}, 0,011 \% \mathrm{P}$ e $0,002 \% \mathrm{~S}$ com espessura inicial de $1,15 \mathrm{~mm}$, dureza de $180 \mathrm{HV} \pm 2 \mathrm{HV}$ avaliada a partir do uso de um microdurômetro Vickers HMV com tempo de indentação igual a 15 segundos e carga de $300 \mathrm{gf}$.

\footnotetext{
* Contribuição técnica ao $69^{\circ}$ Congresso Anual da ABM - Internacional e ao 14ํㅡㄹ ENEMET - Encontro Nacional de Estudantes de Engenharia Metalúrgica, de Materiais e de Minas, 21 a 25 de julho de 2014, São Paulo, SP, Brasil.
} 


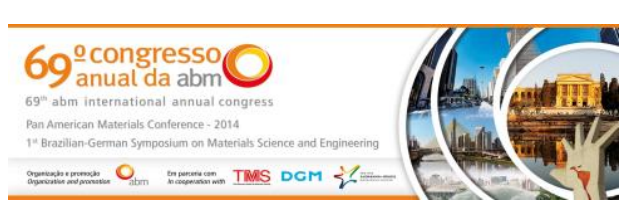

As amostras necessárias à preparação dos corpos de prova de cisalhamento foram submetidas aos tratamentos térmicos de normalização (aquecimento a $800^{\circ} \mathrm{C}$ durante 30 minutos com posterior resfriamento ao ar) e de têmpera (aquecimento a $730^{\circ} \mathrm{C}$ durante 30 minutos com resfriamento em água), sendo ambos os tratamentos térmicos realizados em um forno do tipo mufla do fabricante Magnus.

Essas chapas foram preparadas para a realização do ensaio de cisalhamento cíclico de acordo com as considerações feitas a seguir.

\subsection{Cisalhamento Cíclico}

Os ensaios de cisalhamento foram realizados com uso de um dispositivo montado à máquina de ensaios universais Instron 5582, como registrado por Lopes [8]. Neste caso, fez-se o cisalhamento cíclico mediante a combinação dos cisalhamentos direto e reverso, promovendo assim, a mudança do sentido de deformação plástica do aço Dual Phase.

O carregamento cíclico em cisalhamento foi composto pela combinação dos cisalhamentos direto e reverso, sendo feito dois ciclos para cada valor de deformação efetiva e taxa de deformação escolhidos para a análise do aço Dual Phase.

Considerando esse aspecto, neste trabalho foram escolhidas duas variáveis para estudar o retorno elástico do aço Dual Phase, com uso da técnica de cisalhamento: a quantidade de deformação cíclica, ou seja, a amplitude de deformação cíclica, sendo adotados três valores de deformação efetiva: 0,05; 0,20 e 0,50 e a taxa de deformação: 0,001/s e 0,1/s.

\section{RESULTADOS E DISCUSSÃO}

As Figuras 1 até 3 apresentam os gráficos de tensão efetiva versus deformação efetiva do aço Dual Phase após o cisalhamento cíclico sob taxa de deformação igual a $0,001 / \mathrm{s}$ para os três valores de amplitude de deformação efetiva: 0,05; 0,20 e 0,50, respectivamente.

Os resultados mostram que as curvas referentes ao segundo carregamento cíclico, ou seja, o segundo ciclo de deformação, tendem a se aproximar das curvas do primeiro carregamento cíclico, ou primeiro ciclo, à medida que a amplitude de deformação efetiva cíclica aumenta. Esse fato é explicado pelo endurecimento gradativo que o material experimenta com 0 acréscimo da quantidade de deformação efetiva, sendo isso associado ao encruamento do aço Dual Phase.

Com relação ao retorno elástico, nota-se a partir da análise das Figuras 1 até 3 a tendência de aumento deste fenômeno com o aumento da amplitude de deformação cíclica, sendo isso indicado pelo afastamento da parte inclinada da curva de tensão efetiva-deformação efetiva em relação ao momento de inversão do sentido de deformação plástica, ou seja, no momento da mudança do cisalhamento direto para o cisalhamento reverso, veja a indicação do método de cálculo do retorno elástico com uso das setas na Figura 3.

\footnotetext{
* Contribuição técnica ao $69^{\circ}$ Congresso Anual da ABM - Internacional e ao 14ํㅡㄹ ENEMET - Encontro Nacional de Estudantes de Engenharia Metalúrgica, de Materiais e de Minas, 21 a 25 de julho de 2014, São Paulo, SP, Brasil.
} 

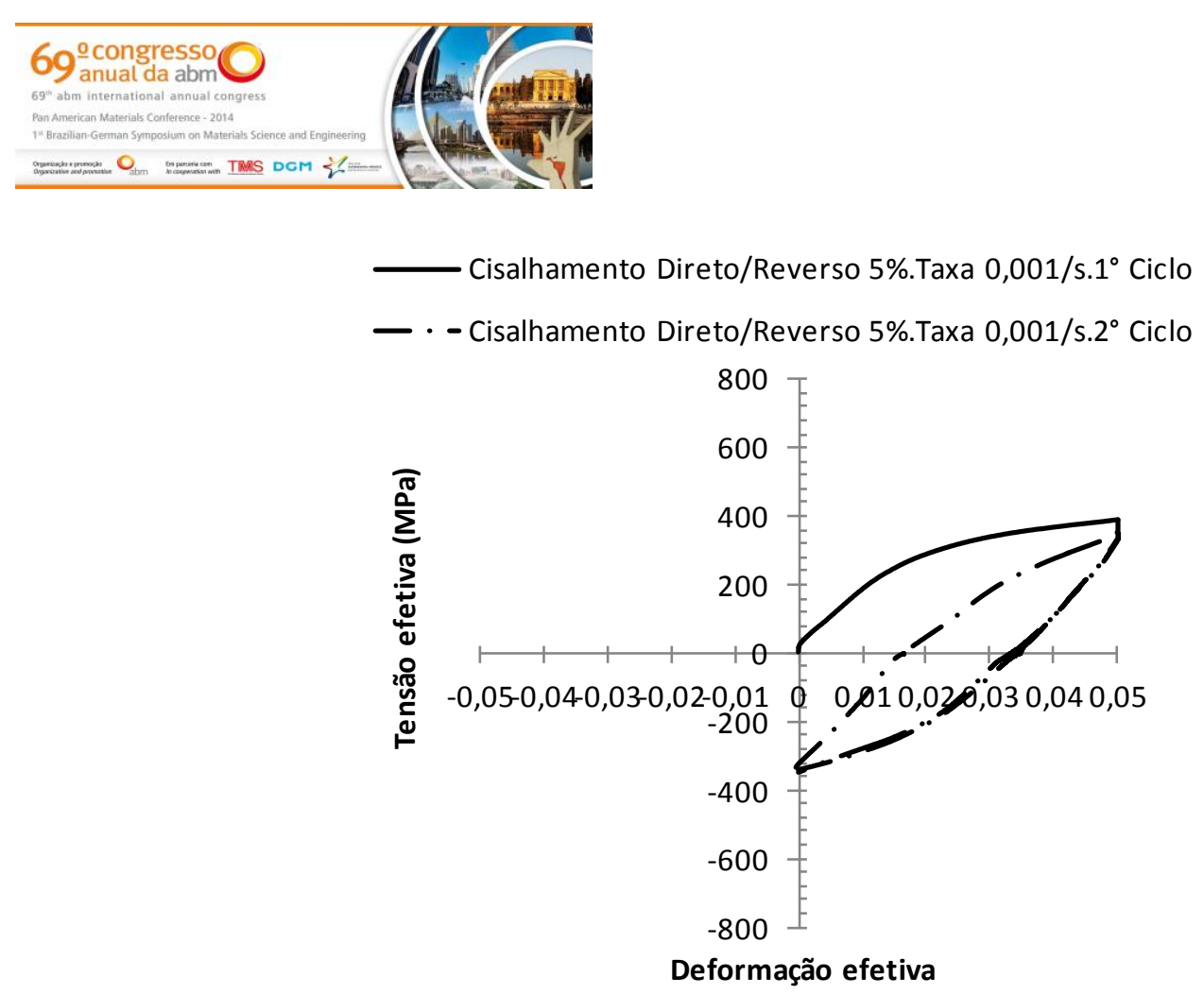

Figura 1. Curvas tensão efetiva-deformação efetiva aço Dual Phase sob cisalhamento cíclico com taxa de deformação de 0,001/s e amplitude de deformação efetiva igual a 0,05.

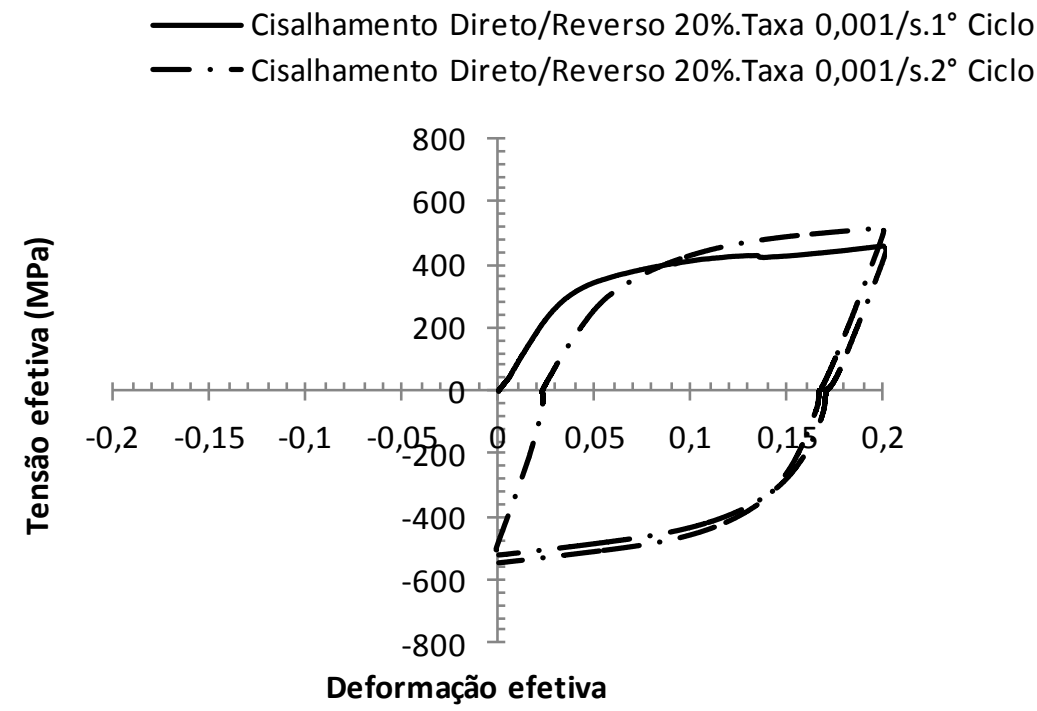

Figura 2. Curvas tensão efetiva-deformação efetiva aço Dual Phase sob cisalhamento cíclico com taxa de deformação de 0,001/s e amplitude de deformação efetiva igual a 0,20.

A Figura 4 exibe a evolução do retorno elástico do aço Dual Phase em função da amplitude de deformação cíclica e do número de ciclos $\left(1^{\circ}\right.$ e $\left.2^{\circ}\right)$ para a taxa de deformação igual a $0,001 / \mathrm{s}$.

Percebe-se o aumento do retorno elástico do aço Dual Phase com o acréscimo da amplitude de deformação cíclica e com o número de ciclos. Esses resultados estão relacionados com aumento do encruamento do aço DP com o valor da amplitude de deformação cíclica e com o número de ciclos, pois para a mesma quantidade de deformação plástica, quando maior o encruamento de um material maior tende a ser o respectivo retorno elástico experimentado pelo mesmo [3].

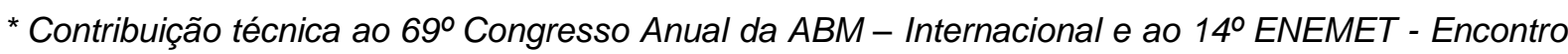
Nacional de Estudantes de Engenharia Metalúrgica, de Materiais e de Minas, 21 a 25 de julho de 2014, São Paulo, SP, Brasil.
} 

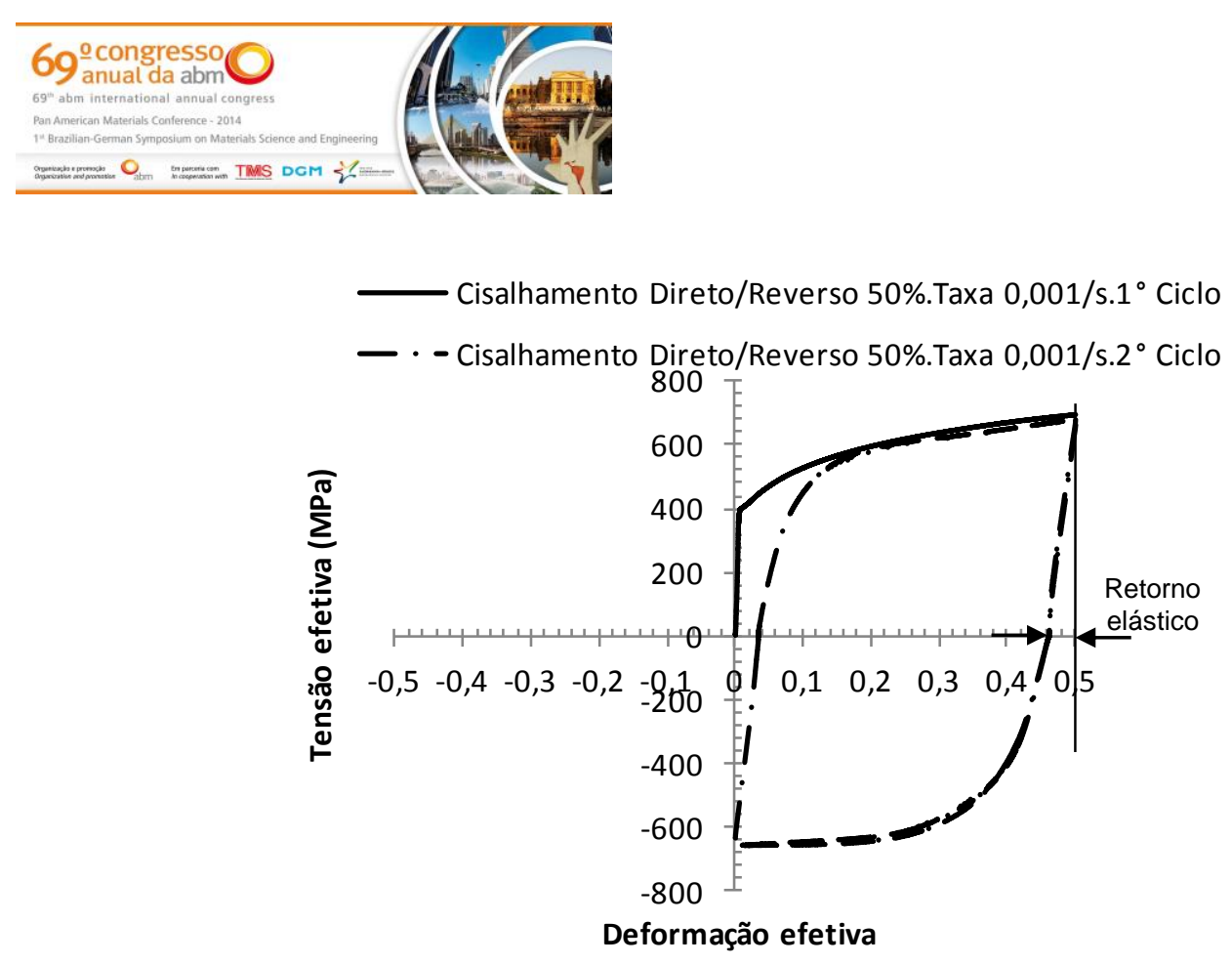

Figura 3. Curvas tensão efetiva-deformação efetiva aço Dual Phase sob cisalhamento cíclico com taxa de deformação de 0,001/s e amplitude de deformação efetiva igual a 0,50.

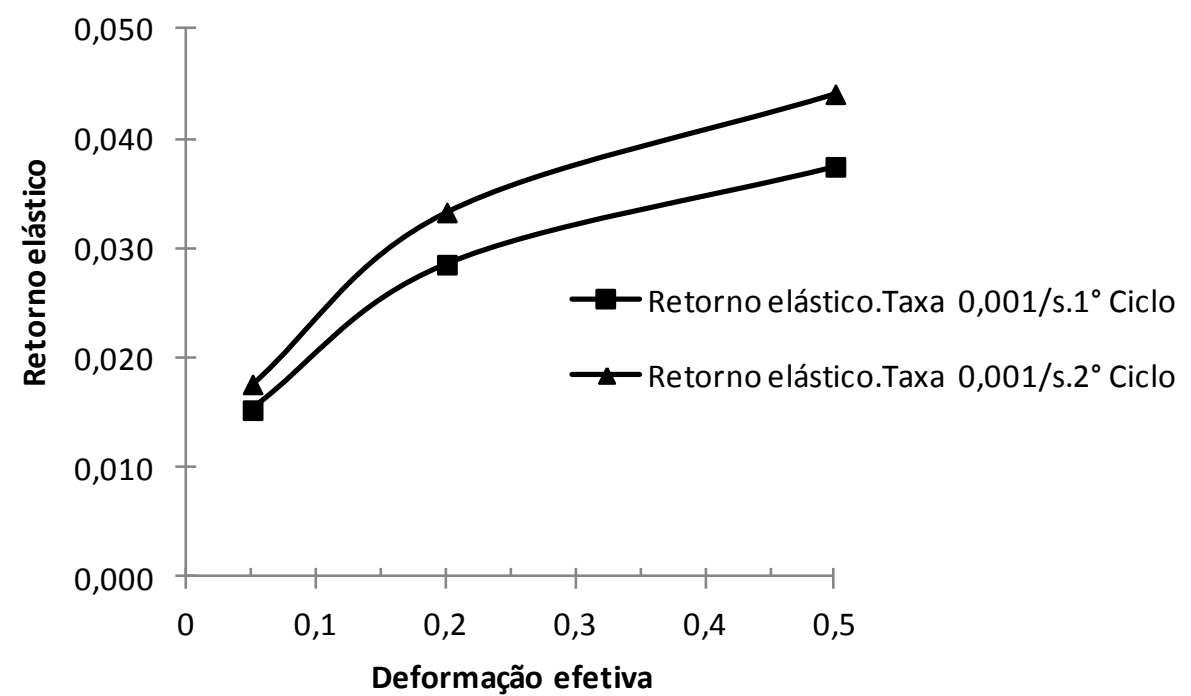

Figura 4. Variação do retorno elástico do aço Dual Phase em função da amplitude de deformação cíclica e do número de ciclos sob taxa de deformação igual a 0,001/s.

De modo análogo, as Figuras 5 até 7 mostram as curvas de tensão efetiva em função da deformação efetiva para os dois ciclos de cisalhamento aplicados ao aço Dual Phase e quantidades de amplitude de deformação cíclica para os ensaios realizados sob taxa de deformação igual a $0,1 / \mathrm{s}$.

Novamente é observada a tendência de aumento do retorno elástico com o aumento da amplitude de deformação cíclica.

Verifica-se ainda a partir da observação da Figura 8 que o retorno elástico para o aço Dual Phase também foi maior com o acréscimo da amplitude de deformação cíclica e com o número de ciclos sob a taxa de deformação igual a $0,1 / \mathrm{s}$. Nota-se também que a diferença do retorno elástico entre o primeiro e o segundo ciclos tornou-se mais evidente somente a partir da amplitude de deformação cíclica superior a 0,05 .

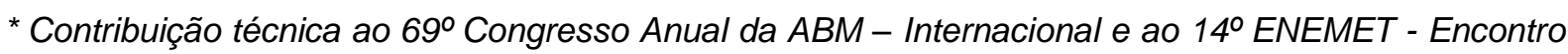
Nacional de Estudantes de Engenharia Metalúrgica, de Materiais e de Minas, 21 a 25 de julho de 2014, São Paulo, SP, Brasil.
} 


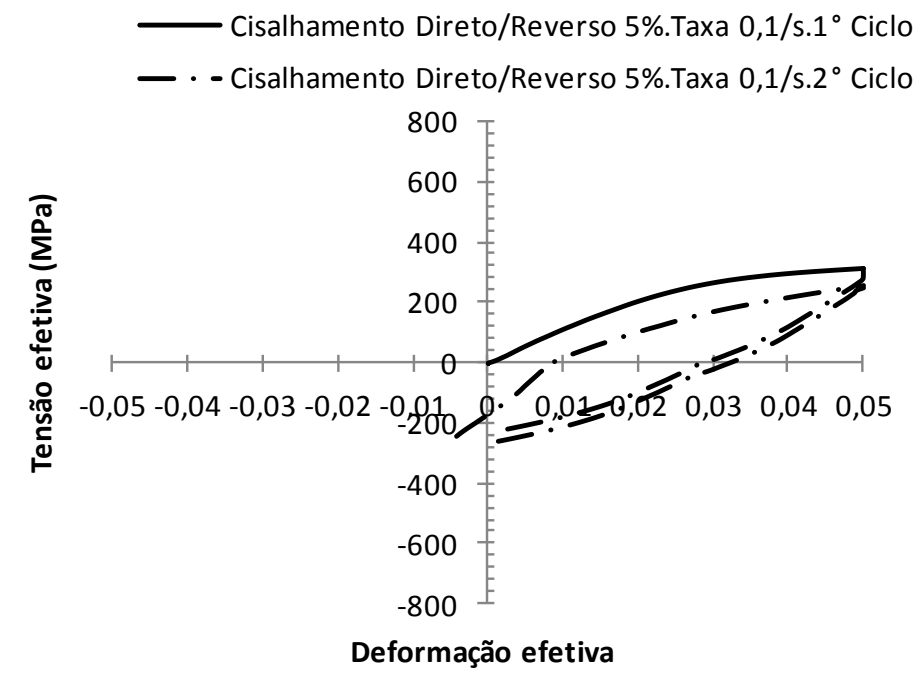

Figura 5. Curvas tensão efetiva-deformação efetiva aço Dual Phase sob cisalhamento cíclico com taxa de deformação de 0,1/s e amplitude de deformação efetiva igual a 0,05.

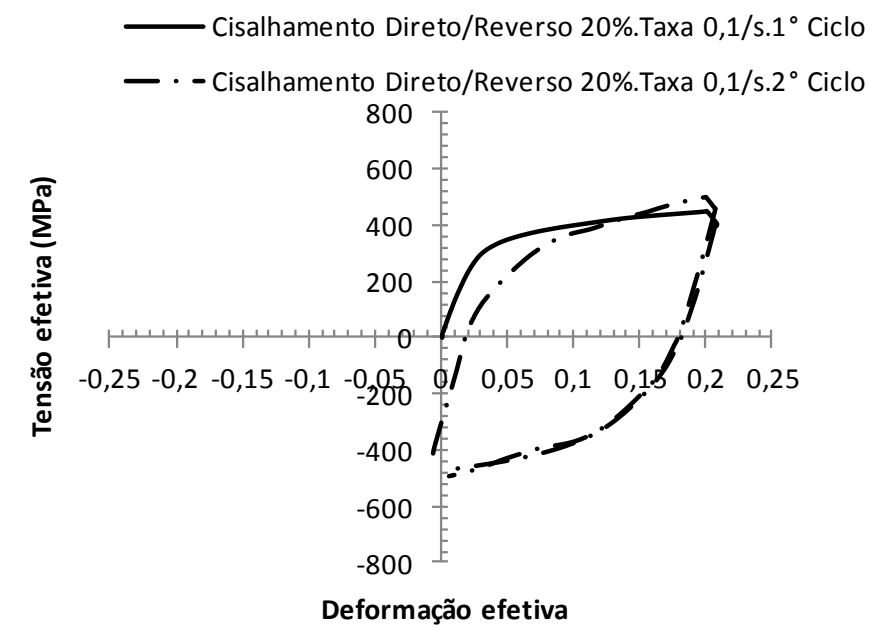

Figura 6. Curvas tensão efetiva-deformação efetiva aço Dual Phase sob cisalhamento cíclico com taxa de deformação de 0,1/s e amplitude de deformação efetiva igual a 0,20.

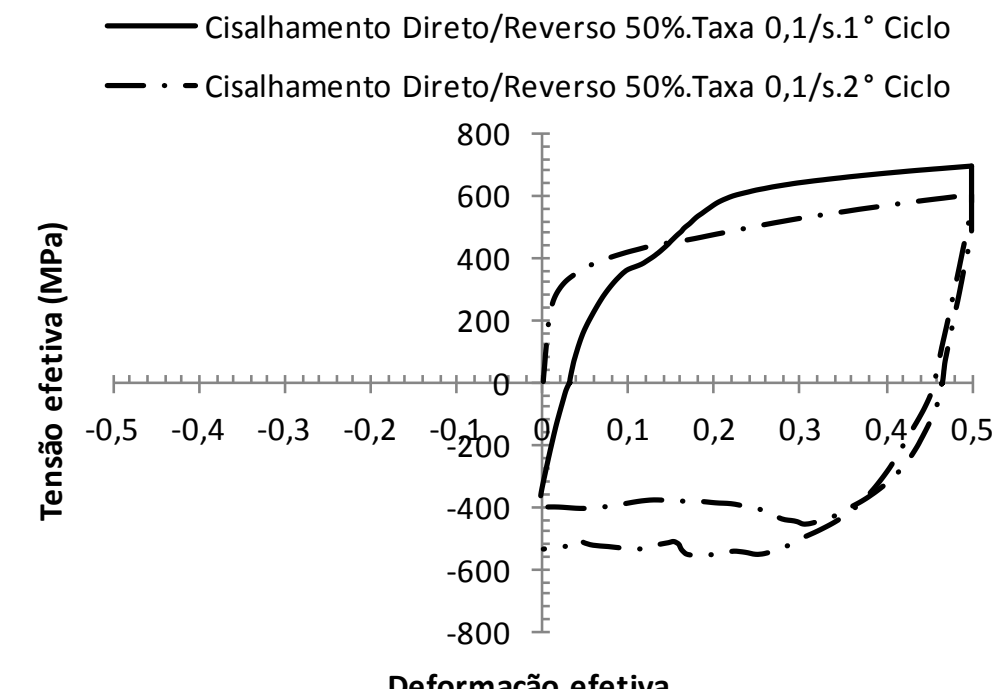

Deformação efetiva

Figura 7. Curvas tensão efetiva-deformação efetiva aço Dual Phase sob cisalhamento cíclico com taxa de deformação de 0,1/s e amplitude de deformação efetiva igual a 0,50.

* Contribuição técnica ao $69^{\circ}$ Congresso Anual da ABM - Internacional e ao 14ํㅡㄹ ENEMET - Encontro Nacional de Estudantes de Engenharia Metalúrgica, de Materiais e de Minas, 21 a 25 de julho de 2014, São Paulo, SP, Brasil. 

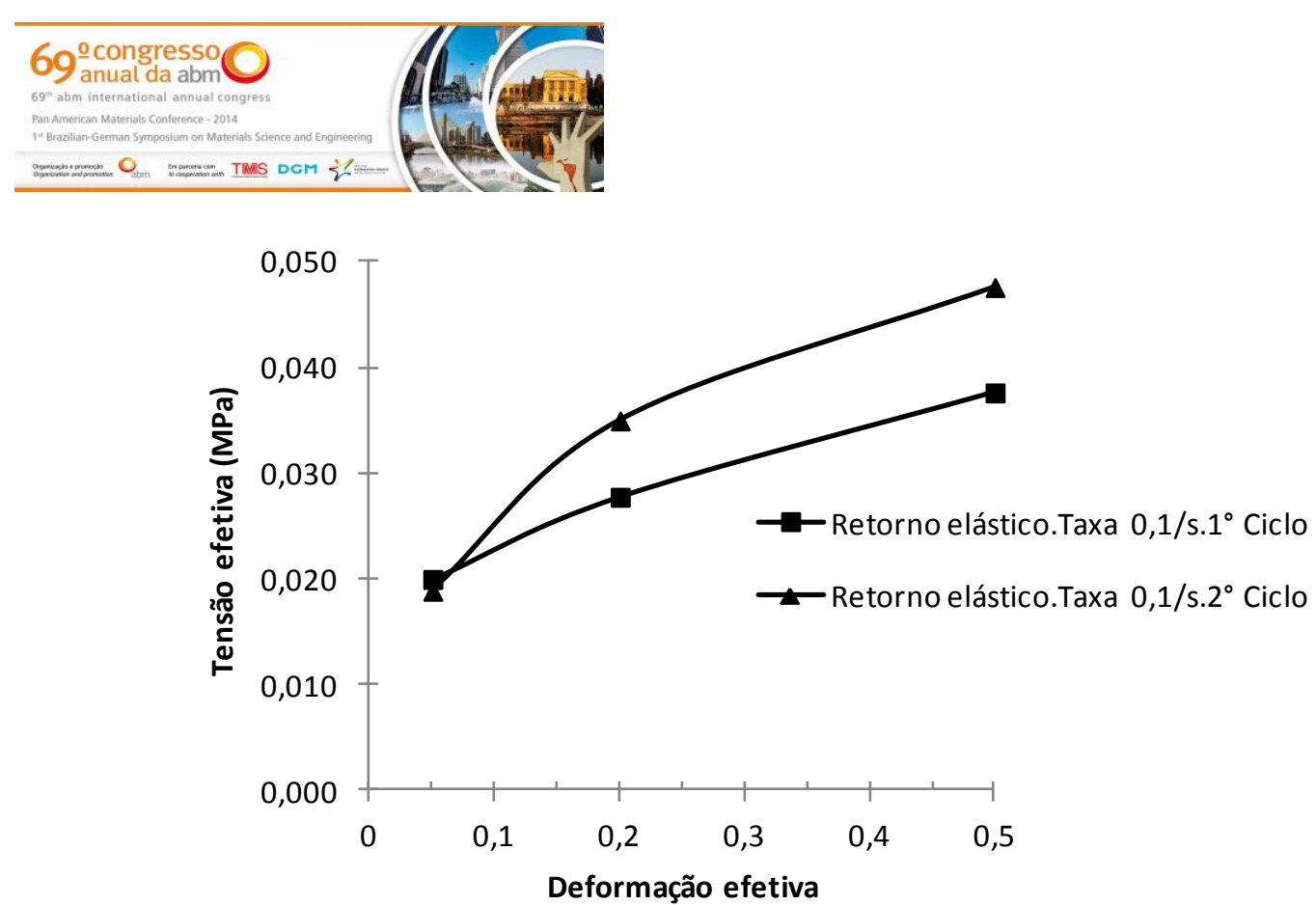

Figura 8. Variação do retorno elástico do aço Dual Phase em função da amplitude de deformação cíclica e do número de ciclos sob taxa de deformação igual a 0,1/s.

Com o objetivo de comparar agora o efeito do valor da taxa de deformação, 0,001/s e $0,1 / \mathrm{s}$, as Figuras 9 e 10 apresentam a variação do retorno elástico do aço Dual Phase em função dessa variável para os três valores de amplitude de deformação cíclica. É possível observar que durante o primeiro ciclo de cisalhamento direto e reverso, Figura 9, a diferença entre o retorno elástico do aço Dual Phase em função do valor da taxa de deformação foi pequena, pois as curvas tendem a se interceptar. No entanto, como discutido antes, para ambos os valores de taxa de deformação, o retorno elástico aumenta com o acréscimo da amplitude de deformação cíclica.

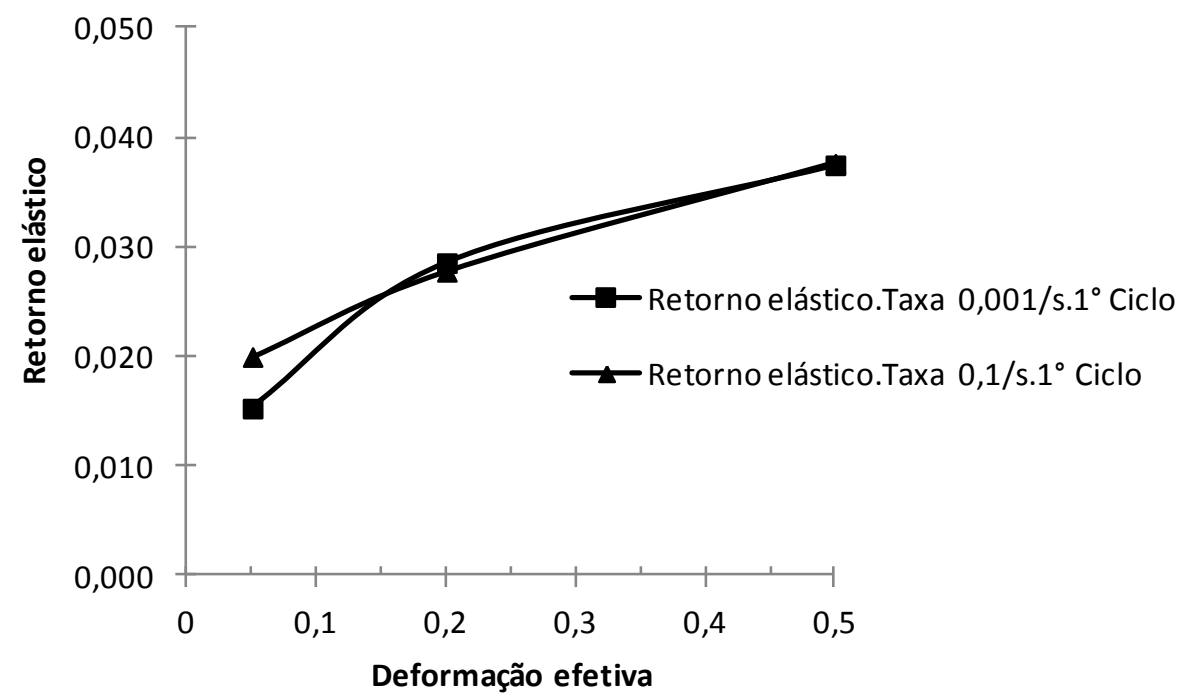

Figura 9. Variação do retorno elástico do aço Dual Phase em função da amplitude de deformação cíclica e da taxa de deformação para o primeiro ciclo de cisalhamento direto/reverso.

O efeito da taxa de deformação no retorno elástico do aço Dual Phase só é notado a partir do segundo ciclo de deformação cisalhante quando se nota o afastamento das respectivas curvas do retorno elástico em função da amplitude de deformação cíclica, Figura 10.

\footnotetext{
* Contribuição técnica ao 69ำ Congresso Anual da ABM - Internacional e ao 14ํㅡㄹ ENEMET - Encontro Nacional de Estudantes de Engenharia Metalúrgica, de Materiais e de Minas, 21 a 25 de julho de 2014, São Paulo, SP, Brasil.
} 

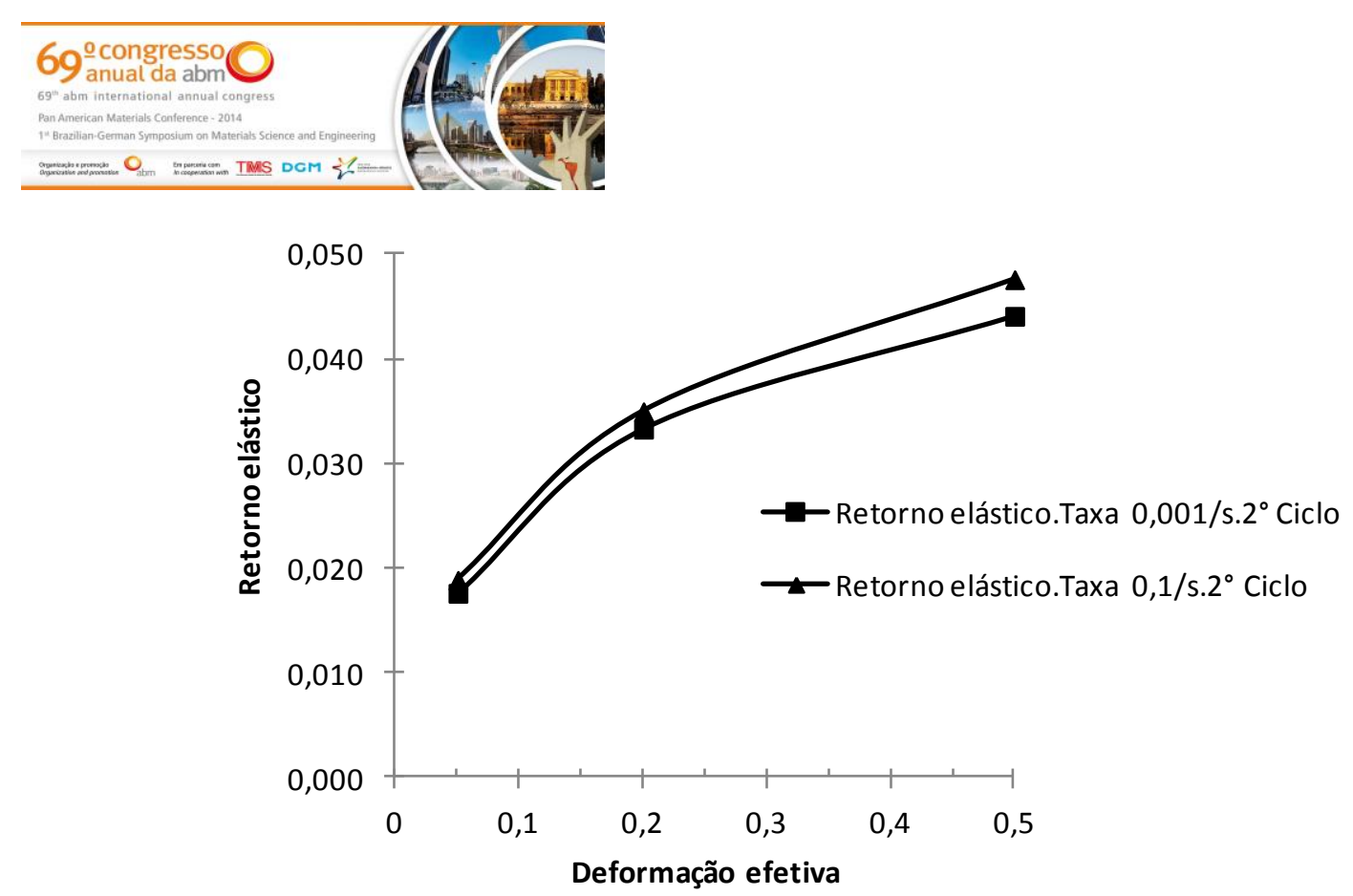

Figura 10. Variação do retorno elástico do aço Dual Phase em função da amplitude de deformação cíclica e da taxa de deformação para o segundo ciclo de cisalhamento direto/reverso.

Esses resultados revelam a eficácia do uso da técnica de cisalhamento planar para promover o estudo do retorno elástico de um material de extrema importância para diversas áreas da conformação mecânica, como a indústria automotiva, como é o caso do aço Dual Phase, assim como para destacar o efeito maior da quantidade de deformação no retorno elástico desse material quando comparado ao exercido pela mudança da taxa de deformação que neste trabalho, só foi percebida para valores de amplitude de deformação cíclica efetiva maiores que 0,05.

\section{CONCLUSÃO}

O estudo do retorno elástico do aço Dual Phase com uso da técnica de cisalhamento planar mediante a combinação de dois ciclos de cisalhamento direto e reverso sob três valores de deformação efetiva e dois valores de taxa de deformação indicaram:

a) o acréscimo do retorno elástico com o aumento da amplitude de deformação efetiva cíclica $(0,05 ; 0,20$ e 0,50$)$ para ambos os valores de taxa de deformação $(0,001 / \mathrm{s}$ e $0,1 / \mathrm{s})$;

b) a similaridade entre o retorno elástico experimentado pelo aço Dual Phase para os dois valores de taxa de deformação e amplitudes de deformação efetiva cíclica durante o primeiro ciclo de cisalhamento direto/cisalhamento reverso;

c) o acréscimo do retorno elástico com o aumento da taxa de deformação a partir do segundo ciclo de deformação efetiva cíclica e amplitude de deformação efetiva superior a 0,05 ;

d) a eficácia do uso da técnica de cisalhamento planar para promover o estudo do retorno elástico do aço Dual Phase quando exposto à condição de carregamento cíclico.

\section{Agradecimentos}

Os autores agradecem à Fapemig e ao CNPq pelo apoio quanto à realização deste trabalho.

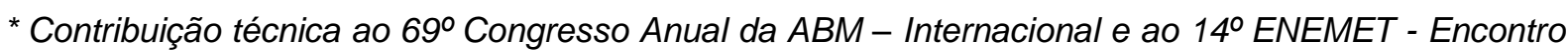
Nacional de Estudantes de Engenharia Metalúrgica, de Materiais e de Minas, 21 a 25 de julho de 2014, São Paulo, SP, Brasil.
} 


\section{REFERÊNCIAS}

1 Haus SA Influência do Efeito Bauschinger no retorno elastic de aços avançados de elevada resistência mecânica [dissertação de mestrado]. Universidade Federal do Paraná; 2011.

2 Banu M, Takamura M, Hama T, Naidim O, Teodosiu C, Makinouchi A. Simulation of springback and wrinkling in stamping of a Dual Phase steel rail-shaped part. J. Mater. Process. Technol. 2006;173:178-184 [acesso em 10 mar. 2014]. Disponível em: http://www.sciencedirect.com/science/article/pii/S0924013605009477

3 Oliveira MC, Alves JL, Chaparro BM, Menezes LF. Study of the influence of workhardening modeling in springback prediction. Inter. J. Plasticity. 2007;23:516-543 [acesso em 10 mar. 2014]. Disponível em: http://www.sciencedirect.com/science/article/pii/S0749641906001161

4 Yilami K, Hino R, Hamasaki H, Yoshida F. Bauschinger effect on springback of clad sheet metals in draw bending. Mater. Trans. 2010;51:1364-66 [acesso em 10 mar. 2014]. Disponível em: http://www.jim.or.jp/journal/e/pdf3/51/07/1364.pdf

5 Singh UP, Maiti SK, Date PP, Narasimhan K. Numerical simulation of the influence of air bending tool geometry on product quality. J. Mater. Process. Technol. 2004;145:269275 [acesso em 10 mar. 2014]. Disponível em: http://www.sciencedirect.com/science/article/pii/S0924013603004436

6 Lei LP, Hwang SM, Kang BS. Finite element analysis and design in stainless steel sheet forming and its experimental comparison. J. Mater. Process. Technol. 2001;110:70-77 [acesso em 10 mar. 2014]. Disponível em: http://www.sciencedirect.com/science/article/pii/S0924013603007354

7 Rauch EF, Gracio JJ, Barlat F. Work-hardening model for polycrystalline metals under strain reversal at large strains. Acta Materialia. 2007;55:2939-48 [acesso em 10 mar. 2014]. Disponível em:

http://www.sciencedirect.com/science/article/pii/S1359645407000511

8 Lopes W, Corrêa ECS, Campos HB, Aguilar MTP, Cetlin PR. Effect of reverse and cyclic shear on the work-hardening of AISI 430 stainless steel. J. Mater. Science. 2009; 44:441-448 [acesso em 10 mar. 2014]. Disponível em:

http://download.springer.com/static/pdf/777/art\%253A10.1007\%252Fs10853-008-31210.pdf?auth66=1395235380_7212de57da75aaedccbf2d963929f9e1\&ext=.pdf

\footnotetext{
* Contribuição técnica ao $69^{\circ}$ Congresso Anual da ABM - Internacional e ao 14ํㅡㄹ ENEMET - Encontro Nacional de Estudantes de Engenharia Metalúrgica, de Materiais e de Minas, 21 a 25 de julho de 2014, São Paulo, SP, Brasil.
} 